\title{
Development of On-line Instrumentation and Techniques to Detect and Measure Particulates
}

\section{Quarterly Technical Progress Report}

From April. 1, 2003 to July 1, 2003

Principle authors: Sheng Wu, Steve Palm, Yongchun Tang, William A.

Goddard III

Date Report was issued: Oct. 31, 2003

DOE Award number: DE-FC26-02NT41581

Name and Address of Submitting Organization:

California Institute of Technology

1200 East California Blvd.,

Pasadena, CA91125 


\section{Disclaimer}

This report was prepared as an account of work sponsored by an agency of the United States Government. Neither the United States Government nor any agency thereof, nor any of their employees, makes any warranty, express or implied, or assumes any legal liability or responsibility for the accuracy, completeness, or usefulness of any information, apparatus, product, or process disclosed, or represents that its use would not infringe privately owned rights. Reference herein to any specific commercial products, process, or services by trade name, trademark, manufacturer, or otherwise does not necessarily constitute or imply its endorsement, recommendation, or favoring by the United States Government or any agency thereof. The views and opinions of authors expressed herein do not necessarily state or reflect those of the United States Government or any agency thereof.

\section{Abstract}

In the fourth quarter of the project, we fixed the interference problem of linear CCD array when collecting elastic scattering signal from laser sources. We collected scattering signal of standard samples and also on a wax formation liquid. The results are compared to theoretical results and demonstrate the clear advantages of such technique v. s. traditional scattering instrument with enclosures or just transmission type of spectrometers. 


\section{Table of Content}

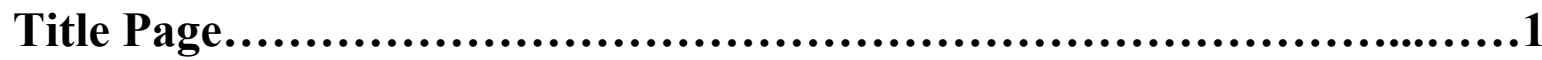

Disclaimer and Abstract...................................................2

Table of Content........................................................3

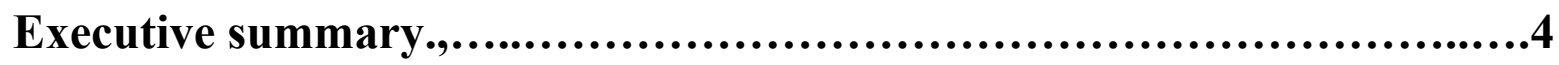

Experimental..........,.....................................................5

Results and Discussion..................................................14

Hypothesis and Conclusions...............................................14

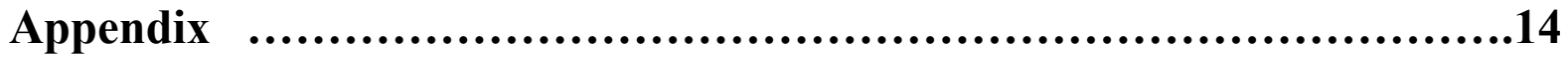




\section{EXECUTIVE SUMMARY}

During the fourth quarter of this project ---- we collected scattering signal on many standard samples with multiple wavelength lasers. We compare our results with theoretical simulation. We also use this setup in our other project --- wax formation process.

1. We measured the angular scattering for multiple particle-standard

- The standard is Polybead Polystyrene microspheres from Polyscienes, Inc (Warrington, PA). The kit includes 5 mono dispersed spheres. We recorded the intensity distribution of scattering for each standard over several concentration levels and over an angular distribution of $+-40 \mathrm{~d}^{\circ}$.

- We had collected the such data in the last quarter by a $532 \mathrm{~nm}$ laser, and found that the data had interference effect as a result of uncoated CCD window. This time, we fixed the problem with a CCD with a window that is carefully removed. We compare the results before and after the removal of the window.

2. We collect scattering signal for a wax formation process --- study dynamic particle formation process

- Besides collecting stable samples at a given time when the user asked the instrument to do, we also developed extra features to the instrument --- by adding programmable recording frequency and record the particle scattering result over a certain period of time.

- We used this program and the instrument setup to measure the formation of wax in our center's petroleum research.

- Our results clearly demonstrate the advantages of such instrument v. s. other instrument such as enclosed angular MIE scattering, or absorption spectrometers. 


\section{EXPERIMENTAL}

1. Measurement of Standard Particles

a. Standard description

The Polybead Polystyrene particles are from Polysciences, Inc. (Warrington, PA). The

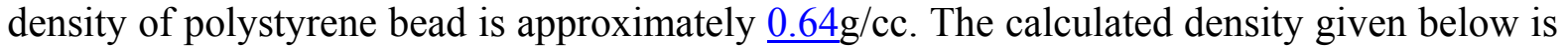
for the original samples.

\begin{tabular}{|l|l|l|l|l|l|}
\hline Size $(\mu \mathrm{m})$ & 0.548 & 0.754 & 0.992 & 2.0 & 3.176 \\
\hline Concentration & $2.6 \%$ & $2.57 \%$ & $2.6 \%$ & $2.6 \%$ & $2.57 \%$ \\
\hline $\begin{array}{l}\text { Std. } \\
\text { Deviation } \\
(\mu \mathrm{m})\end{array}$ & 0.016 & 0.01 & 0.026 & 0.046 & 0.156 \\
\hline $\begin{array}{l}\text { Calculated } \\
\text { density }(/ \mathrm{ml})\end{array}$ & $4.7^{*} 10^{11}$ & $1.8^{*} 10^{11}$ & $8.0^{*} 10^{10}$ & $1.3^{*} 10^{10}$ & $2.4^{*} 10^{9}$ \\
\hline
\end{tabular}

During experiment such concentration is too high so that secondary scattering is obvious, and we diluted to $\sim 1 / 1000^{\text {th }}$ the original concentration. We then measure the scatting signal for several concentrations ranging from $1 / 1000^{\text {th }}$ to $1 / 100^{\text {th }}$ the original concentration and compare the angular distribution.

The setup for collecting angular distribution is shown in the schematic and the picture below,
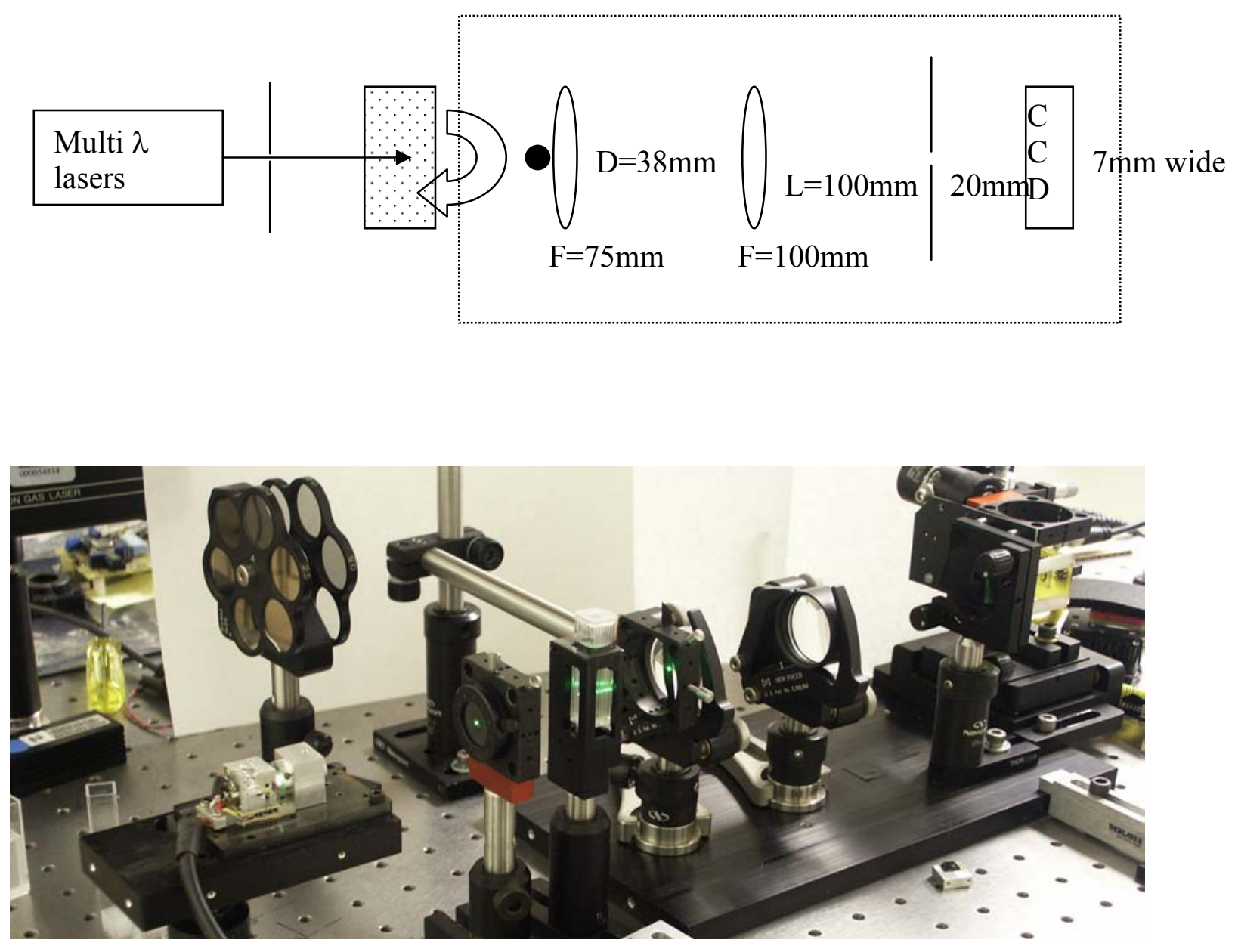
b. In our previous report, we give results of scattering for such standards, but we found that the signal quality was compromised significantly by the interference effect from the $\mathrm{CCD}$ detector window.

Below we give a typical plot of the scattered signal collected with a normal CCD with uncoated BK7 window.

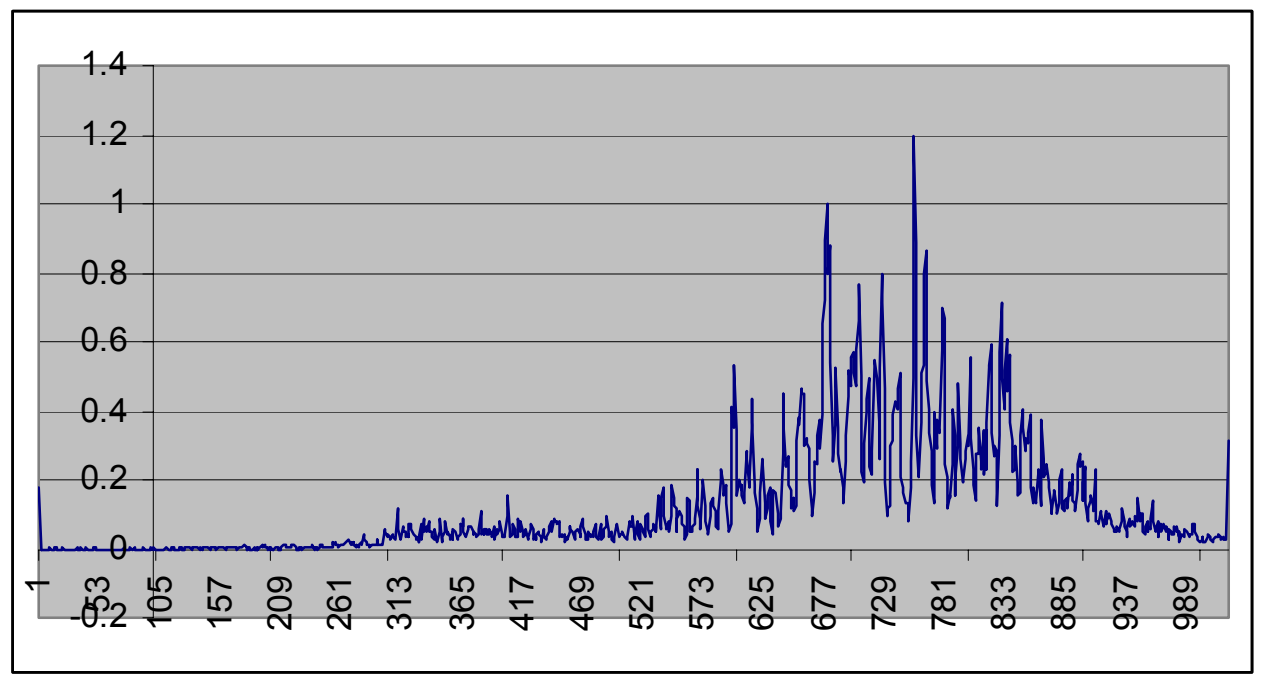

We observed strong fast modulation on top of the scattered signal profile. The fast (along the pixels positions, $>30 \% \sim 50 \%$ modulation in less than 15 pixels) modulation comes from the interference effect of the uncoated window, which introduces modulation as large as $50 \%$ when the detected signal is coherent and monochromatic laser light. For incoherent light, one does not observe such kind of interferences. We found this problem and then try to remove the window by careful grinding.

We succeeded in grinding 2 ELIS1024 chips from some 8 original chips. The finished sample is show in the picture below along with another CCD chip (LIS1024), which has a

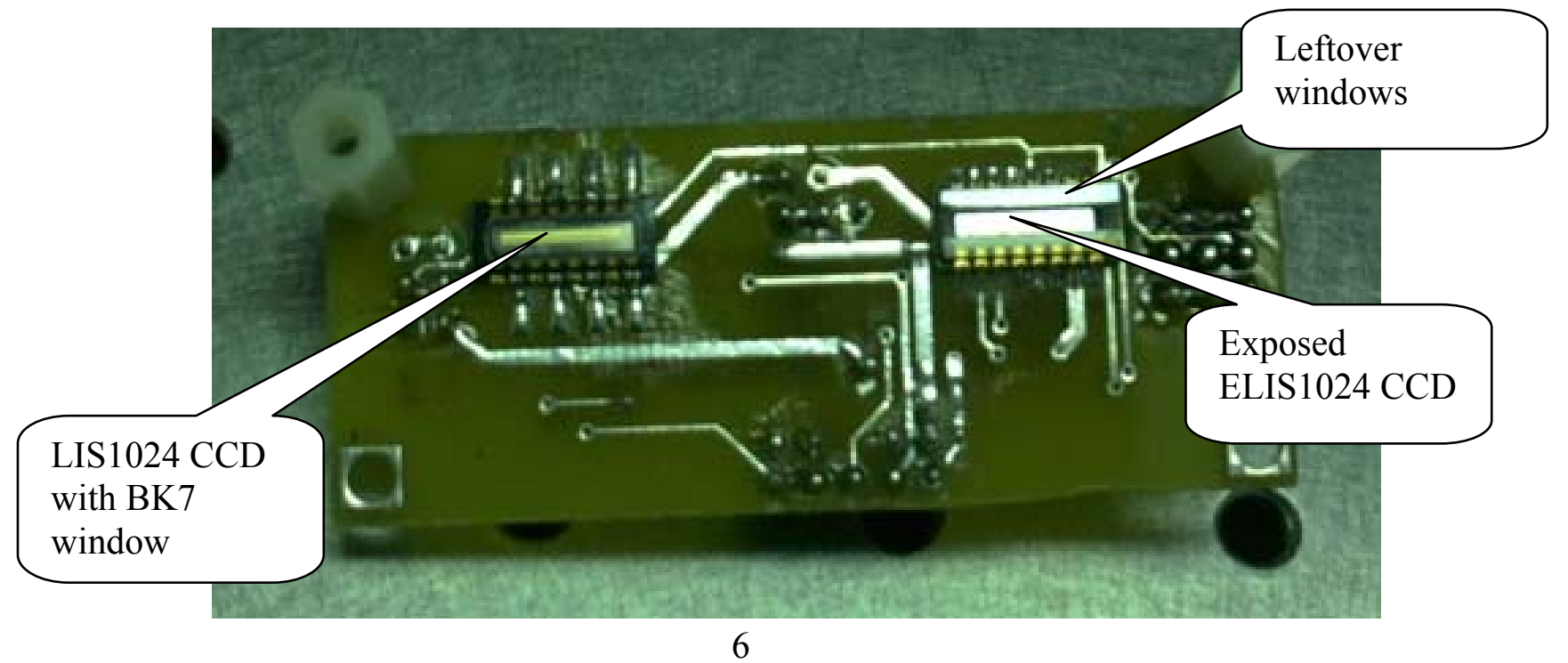


normal BK7 window. The reflected shadow image formed by the BK7 window is clearly shown with the LIS chip, while the ELIS chip has its sensor area exposed.

The resulting scattering certainly shows much smoother scattered signal along the pixel positions. As shown by the plot below on the left, the plot is recorded with a laser beam (1 $\mathrm{mm}$ diameter, collimated) passing through a $100 \mu \mathrm{m}$ diameter pin-hole, and then detected by $\mathrm{CCD}$ at $20 \mathrm{~mm}$ away from the pin-hole. With each pixel's width is $7 \mu \mathrm{m}$, this gives the
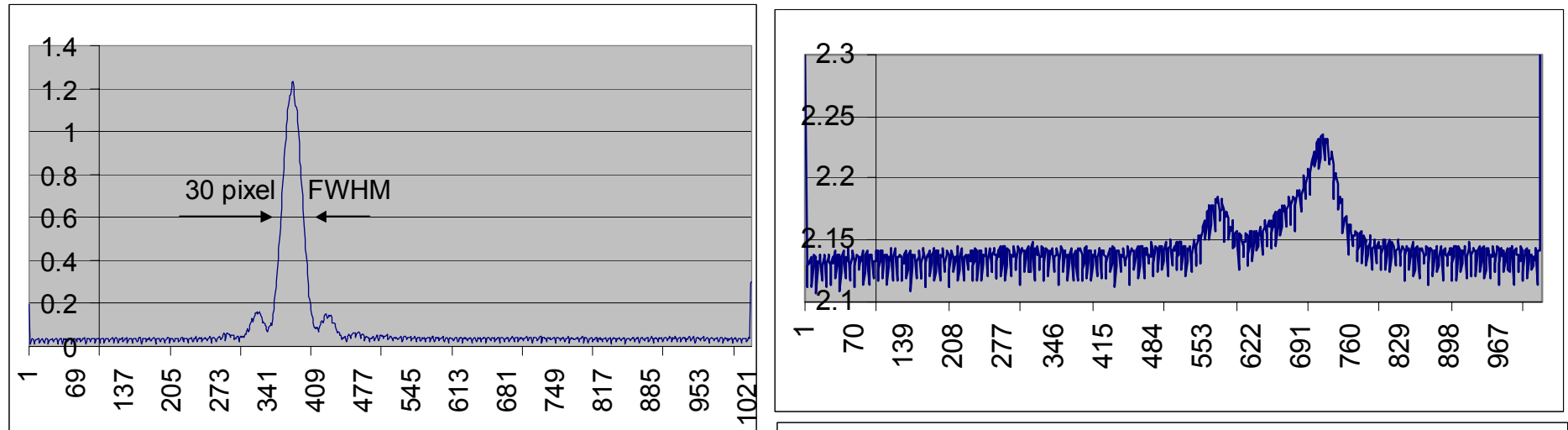

angular resolution of 1 degree for every 30 pixels. On the right, 3 plots shows the same scan when the sample is replaced by a piece of paper --- now it is a point scattering source and scattering is quite broad angular distribution. We could see that this optical system could let simultaneous recording of scattering signal over an angular range of $\sim 30^{\circ}$.
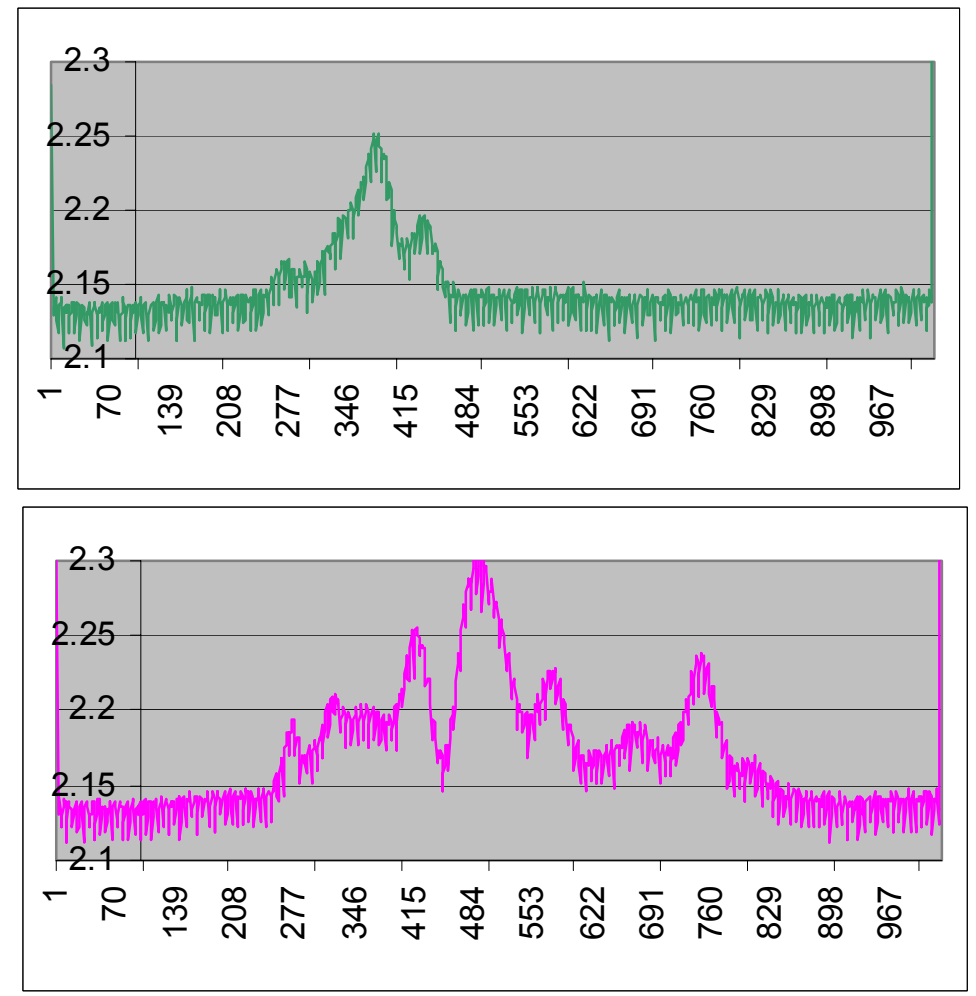

c. Standard samples

We are in the process of collecting over 1,000 scans ( $1 \mathrm{k}$ pixel each scan) of data for these 5 different samples, under different wavelengths (10) and concentrations (5 each), over an angular range of $+-50^{\circ}$. Here is just 2 of the typical scans for $1.87 \mu \mathrm{m}$ particles with concentration at $10^{6}$ (left) and $10^{9}$ (right) $/ \mathrm{ml}$. 

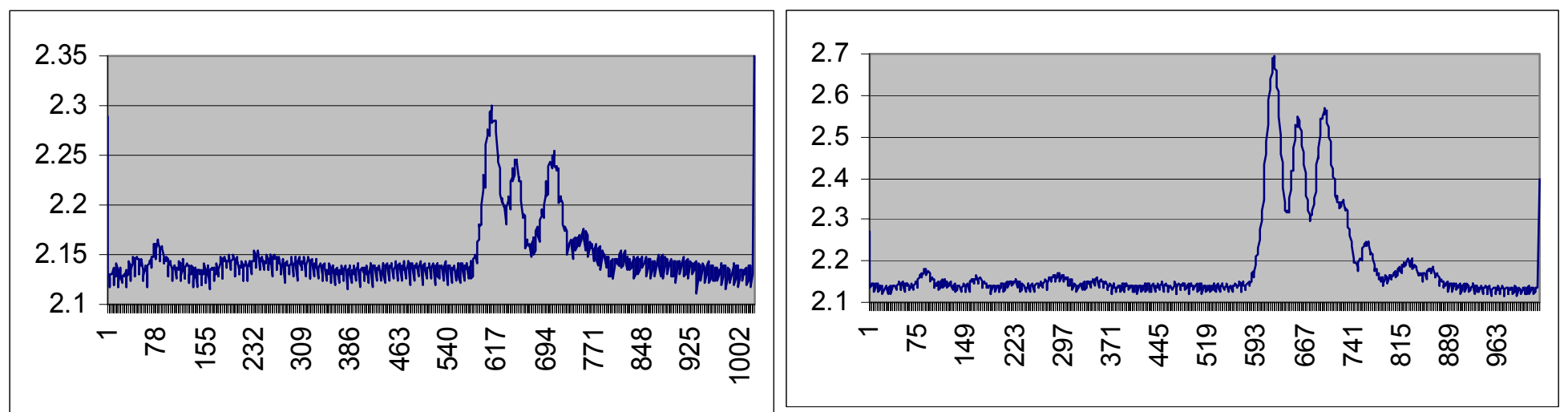

We will collect more such standard scans on many more sample, including samples in the air in the next 3 months and will form a database for future instrumentation. Much of these data has not been collected before and we will submit a paper on this soon.

With so much data, we are also designing a program that let us easily archive, search and review/reuse such database. This program will be necessary for the use of this database.

2. Recording light scattering signal in a dynamic process

One of the major advantages that we hope to achieve with this instrument is the online diagnostics of particulate matters. This could be applied not just to continuous emission monitoring, but also to study of dynamics in particle formation.

In our PEER center, we are trying to find wax inhibitor for better oil transportation. One major question here is to be able to tell the particle size distribution and concentration at different temperatures when different inhibitors are added. Here, with the setup above and more advanced software features, such as programmable timed recording, we studied the wax formation in decane (C10) liquid. In this setup, one could define the frequency of the recording the scattering signal, and also control the external camera to take pictures in synchronized fashion.

The page below shows a series of scattering plots and picture of the solution at different time (the number on each plot is the time in minutes). We could see that there is no scattering when there is no wax. As wax appears, a certain pattern appears in the scattering plot, and grows fast with the wax formation. Then the shape of the scattered plot changes, indicating a change in particle shape/size, and eventually decreases a little because of strong secondary scattering loss.

We are in the process of studying this process using multiple laser wavelengths. The results clearly indicate that the scattering instrument here is much more advantageous compared to spectrometers (loss absorption type), and also other MIE scattering instrument which requires enclosures. 

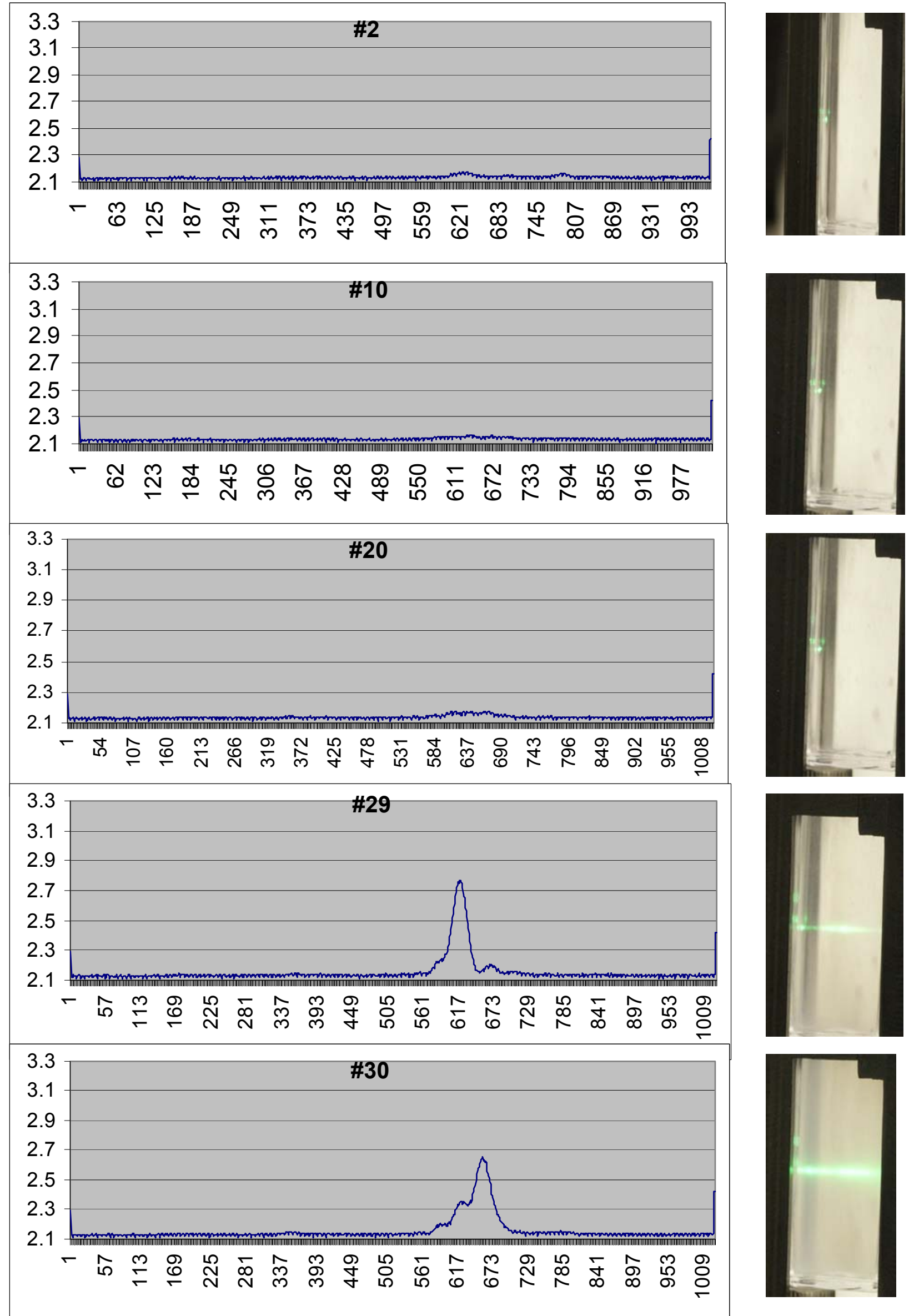
3. Theoretical simulation and multi-wavelength laser setup

a. Simulation

Our theoretical simulation program has also been used to give simulation results that are consistent to the scans above. So far, the results repeats the previous published results by other groups, and qualitatively consistent with our scans in terms of basic shape. But, there are inconsistency when we trying to correlate the signal strength and shape at larger angles. We are trying to figure out what exactly the causes of this inconsistency.

b. Multi-wavelength laser setup

We have decided to use the schematic of arranging multi-wavelength lasers around a small angle distribution. As shown below, and the advantage of this setup is the simplicity of the setup, and being able to fire one laser at a time --- this could also let us use a simple cheap monochromatic CCD detector, instead of the multiple color ones that we proposed last time.

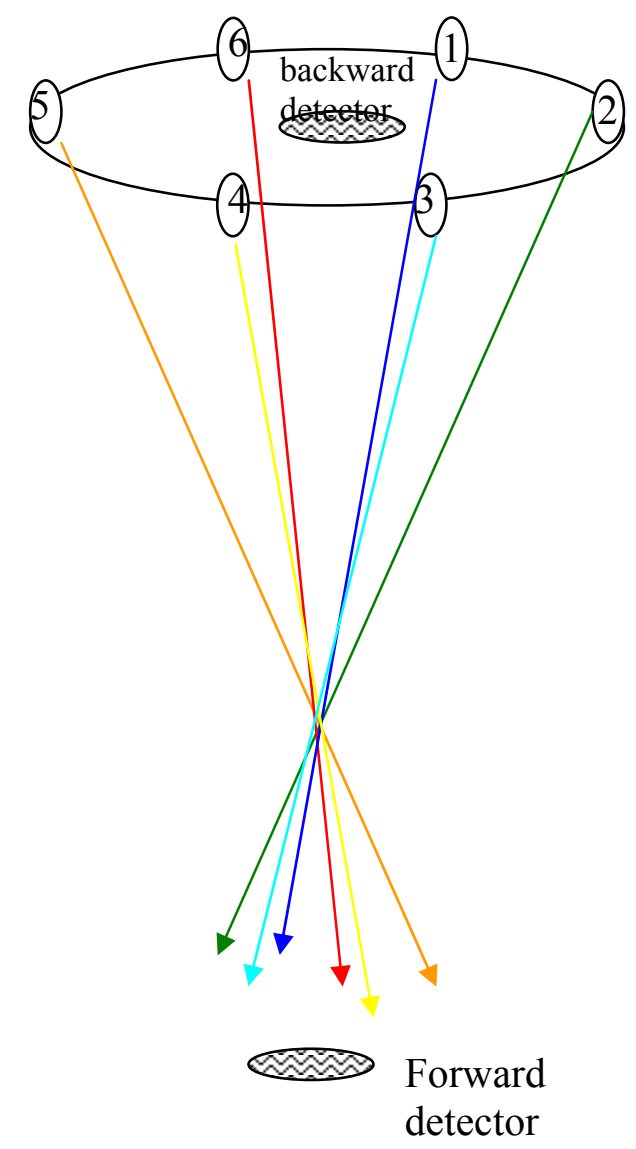




\section{RESULTS AND DISCUSSION}

\section{Experimental results}

We have collected over 200 scans of the standard samples at different concentration and wavelengths, at an angular range of $+-50^{\circ}$, and this work will continue into the next 3 months. These data has never been available before, it not only forms the database for our instrumentation in the next year, but also will be published immediately.

Our simulation also confirms the experimental scans qualitatively, but more work is needed to correlate the experimental results and simulation more consistently.

2. Multi-wavelength laser setup.

We have constructed a multi-wavelength (9 wavelength) laser setup in a 6" diameter ring and they are pointed at the same spot. The pointing angle of each laser is fixed --- we hope that in the next 3 months, we will use an achromatic lens to focus all lasers into the focal spot. The focus of all the laser beams can be changed by a change of the achromatic lens. We will test this scheme also with some samples and compare with database.

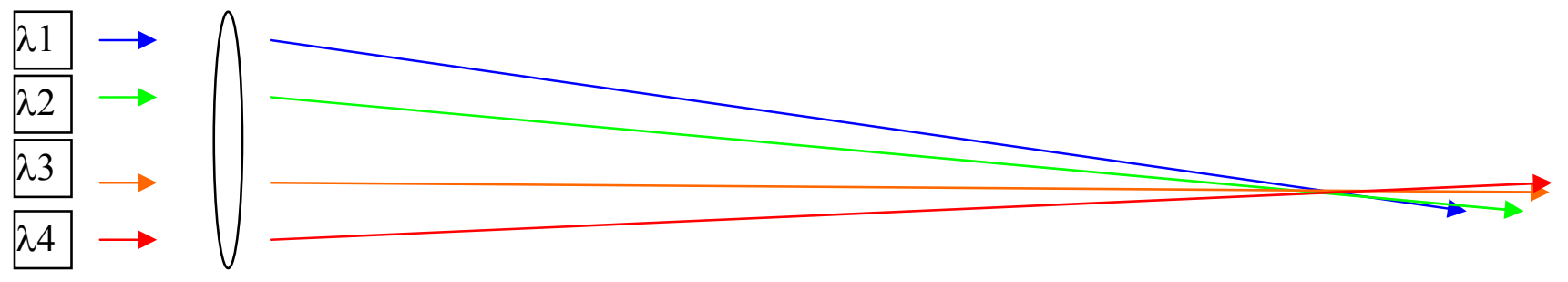

3. Review of the past year progress

In the past year, we have met the schedule in constructing the prototype instrument, which involves laser diode driver, diode pumped laser construction, multi-wavelength laser assembly, CCD sensor and data acquisition system. We also started database collection. Our designs meet the requirements proposed in the proposal in terms of cost and capability. The data we collected are original and will provide the research community with a very good database. Also, we have applied this instrumentation to our center's research on wax inhibitor study and the preliminary results are quite promising.

\section{HYPOTHESIS AND CONCLUSIONS}

This past quarter proceeded as planed and spent the major portion of our time collecting scattering signal for different standard particles. The results are qualitatively verified with simulation. The new database is original and will be published. We also applied our instrument to the study of wax inhibitors and the results are exciting.

This past year work has met the schedule in our statement of work. We will be getting ready for a truly portable field instrument for our work next year. 
Appendix:

Planed schedule from the statement of work

\begin{tabular}{|c|c|c|}
\hline Task & Technical Milestone & Schedule \\
\hline \multirow[t]{2}{*}{$\begin{array}{l}\text { 1. Assembly of the multiwavelength } \\
\text { light source }\end{array}$} & $\begin{array}{l}\text { Ready diode \& DP chip lasers, } \\
\text { drivers }\end{array}$ & Month 1-6 \\
\hline & Ready beam combination system & Month 1-6 \\
\hline $\begin{array}{l}\text { 2. Construction of the PM } \\
\text { synthesizer }\end{array}$ & $\begin{array}{l}\text { Verify that monosize PM are } \\
\text { generated }\end{array}$ & Month 1-6 \\
\hline \multirow{2}{*}{$\begin{array}{l}\text { 3. Simulation of Ralyeigh and Mie } \\
\text { Scattering }\end{array}$} & Literature review & Month 1-3 \\
\hline & $\begin{array}{l}\text { reviewComputer program that } \\
\text { could generate simulated } \\
\text { scattering spectrum }\end{array}$ & Month 1-6 \\
\hline \multirow[t]{2}{*}{$\begin{array}{l}\text { 4. Laboratory demonstration of } \\
\text { instrument }\end{array}$} & $\begin{array}{l}\text { Experimental } r \text { scattering } \\
\text { spectrum database for different } \\
\text { PM sizes }\end{array}$ & \multirow[t]{2}{*}{ Month 7-18 } \\
\hline & $\begin{array}{l}\text { Compare with theory and } \\
\text { conventional PM monitoring } \\
\text { data }\end{array}$ & \\
\hline $\begin{array}{l}\text { 5.Application of the PM analyzer to } \\
\text { a combustion environment: engine } \\
\text { intake area }\end{array}$ & $\begin{array}{l}\text { Correlation of our instrument } \\
\text { data with conventional PM } \\
\text { monitoring data }\end{array}$ & Month 13-24 \\
\hline $\begin{array}{l}\text { 6.Application of the PM analyzer to } \\
\text { a combustion environment: engine } \\
\text { exhaust }\end{array}$ & $\begin{array}{l}\text { Correlation of our instrument } \\
\text { data with total PM mass } \\
\text { emission, new data (PM size and } \\
\text { chemical composition) about in- } \\
\text { situ PM monitoring }\end{array}$ & Month 13-24 \\
\hline $\begin{array}{l}\text { 7. Applicability assessment for PM } \\
\text { emissions from coal fired power } \\
\text { plants }\end{array}$ & $\begin{array}{l}\text { Design/modify our } \quad \text { PM } \\
\text { instrument for smoke stack } \\
\text { monitoring }\end{array}$ & Month 24-30 \\
\hline 8. Instrument design optimization & $\begin{array}{l}\text { Optimize the instrument during } \\
\text { different experiments }\end{array}$ & Month 13-36 \\
\hline
\end{tabular}

